NIST IR 7963

\title{
Evaluation of Energy Consumption Rating Methods for Thermoelectric Wine Chillers and Compact Refrigerators
}

David A. Yashar

Young-Jin Baik

http://dx.doi.org/10.6028/NIST.IR.7963

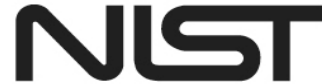

National Institute of Standards and Technology U.S. Department of Commerce 
NIST IR 7963

\title{
Evaluation of Energy Consumption Rating Methods for Thermoelectric Wine Chillers and Compact Refrigerators
}

\author{
David A. Yashar \\ Young-Jin Baik \\ Energy and Environment Division \\ Engineering Laboratory
}

http://dx.doi.org/10.6028/NIST.IR.7963

September 2013

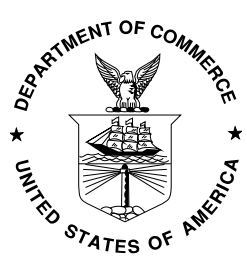

U.S. Department of Commerce

Penny Pritzker, Secretary

National Institute of Standards and Technology Patrick D. Gallagher, Under Secretary of Commerce for Standards and Technology and Director 


\title{
EVALUATION OF ENERGY CONSUMPTION RATING METHODS FOR THERMOELECTRIC WINE CHILLERS AND COMPACT REFRIGERATORS
}

\author{
David A. Yashar and Young-Jin Baik \\ National Institute of Standards and Technology \\ Gaithersburg, MD 20899
}

\begin{abstract}
Most types of refrigerating appliances are rated according to the HRF-1 test method developed by the Association of Home Appliance Manufacturers (AHAM) and their energy use is regulated by the US Department of Energy. These products generally use vapor compression system to maintain a cold internal temperature. Recently, several small products have emerged which use a thermoelectric cooling module instead, an alternate technology with a vastly different method of operation. This study examines whether the HRF-1 test method can be used to rate units that employ thermoelectric cooling modules. Three units were examined in this study and each one was incapable of maintaining the standardized compartment temperatures that are the basis for the rating method, indicating that the test is not applicable. An alternate rating method was explored, which measures the appliance's energy consumption while it operates in a cooler environment than that prescribed in the test. Presented results show that this adjustment to the test method does allow the products to operate in a manner that makes it possible to characterize their performance.
\end{abstract}

Keywords: energy consumption, thermoelectric refrigerator, thermoelectric wine chiller 


\section{Acknowledgement}

This study was sponsored by the United States Department of Energy, Office of Energy Efficiency and Renewable Energy under the supervision of Lucas Adin. Dr. Harrison Skye of NIST and Dr. Detlef Westphalen of Navigant Consulting Inc. provided technical commentary on the draft of this report. 


\section{Table of Contents}

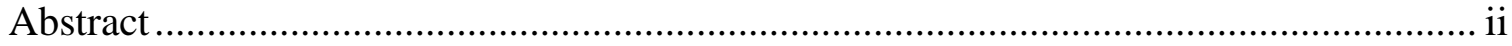

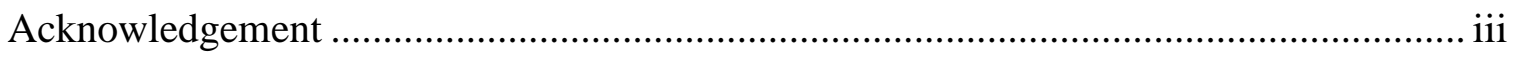

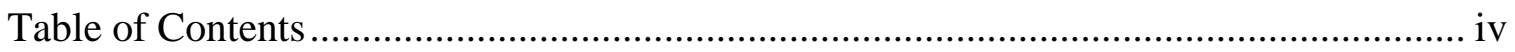

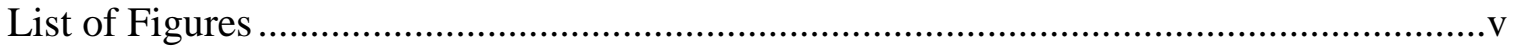

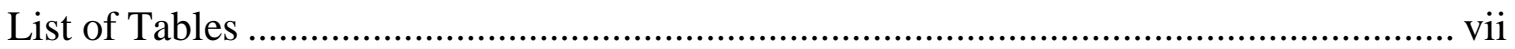

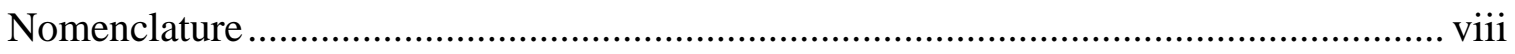

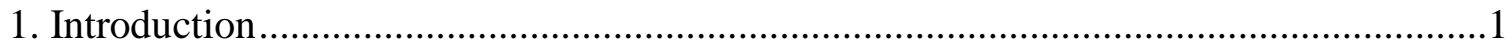

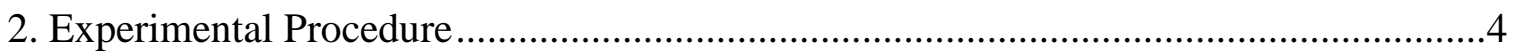

3. Thermoelectric 12-Bottle Wine Chiller .................................................................5

4. Thermoelectric 28-Bottle Wine Chiller ..................................................................

5. Thermoelectric Compact Refrigerator .....................................................................9

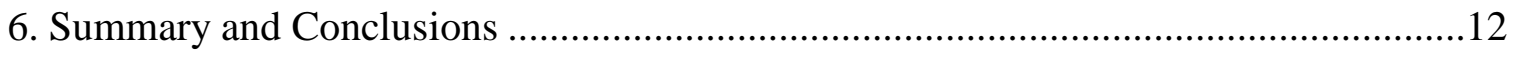

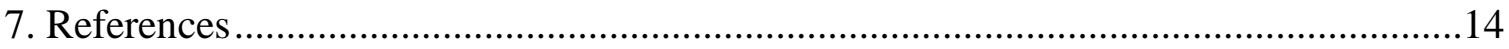




\section{List of Figures}

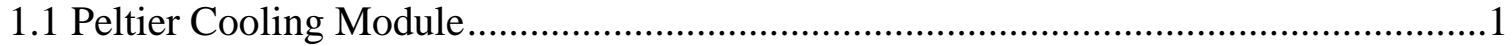

3.1 Thermoelectric 12-Bottle Wine Chiller ..................................................................5

4.1 Thermoelectric 28-Bottle Wine Chiller ...............................................................

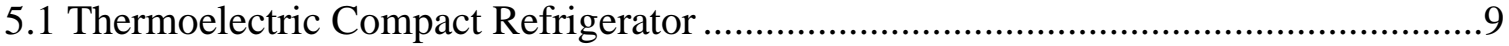

5.2 Compartment Temperature and Power Draw for Thermoelectric Compact

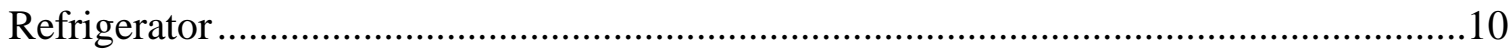




\section{List of Tables}

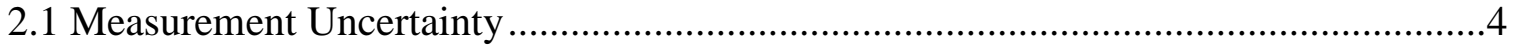

3.1 Test Results for $12-$ Bottle Wine Chiller in $32.2{ }^{\circ} \mathrm{C}$ Test Room .................................6

3.2 Test Results for 12 -Bottle Wine Chiller in $22.2{ }^{\circ} \mathrm{C}$ Test Room ...................................6

4.1 Test Results for 28-Bottle Wine Chiller in $32.2^{\circ} \mathrm{C}$ Test Room ...................................8

4.2 Test Results for 28-Bottle Wine Chiller in $22.2{ }^{\circ} \mathrm{C}$ Test Room ..................................8

5.1 Test Results for Thermoelectric Compact Refrigerator in $32.2{ }^{\circ} \mathrm{C}$ Test Room............10

5.2 Test Results for Thermoelectric Compact Refrigerator in $32.2{ }^{\circ} \mathrm{C}$ Test Room............10 


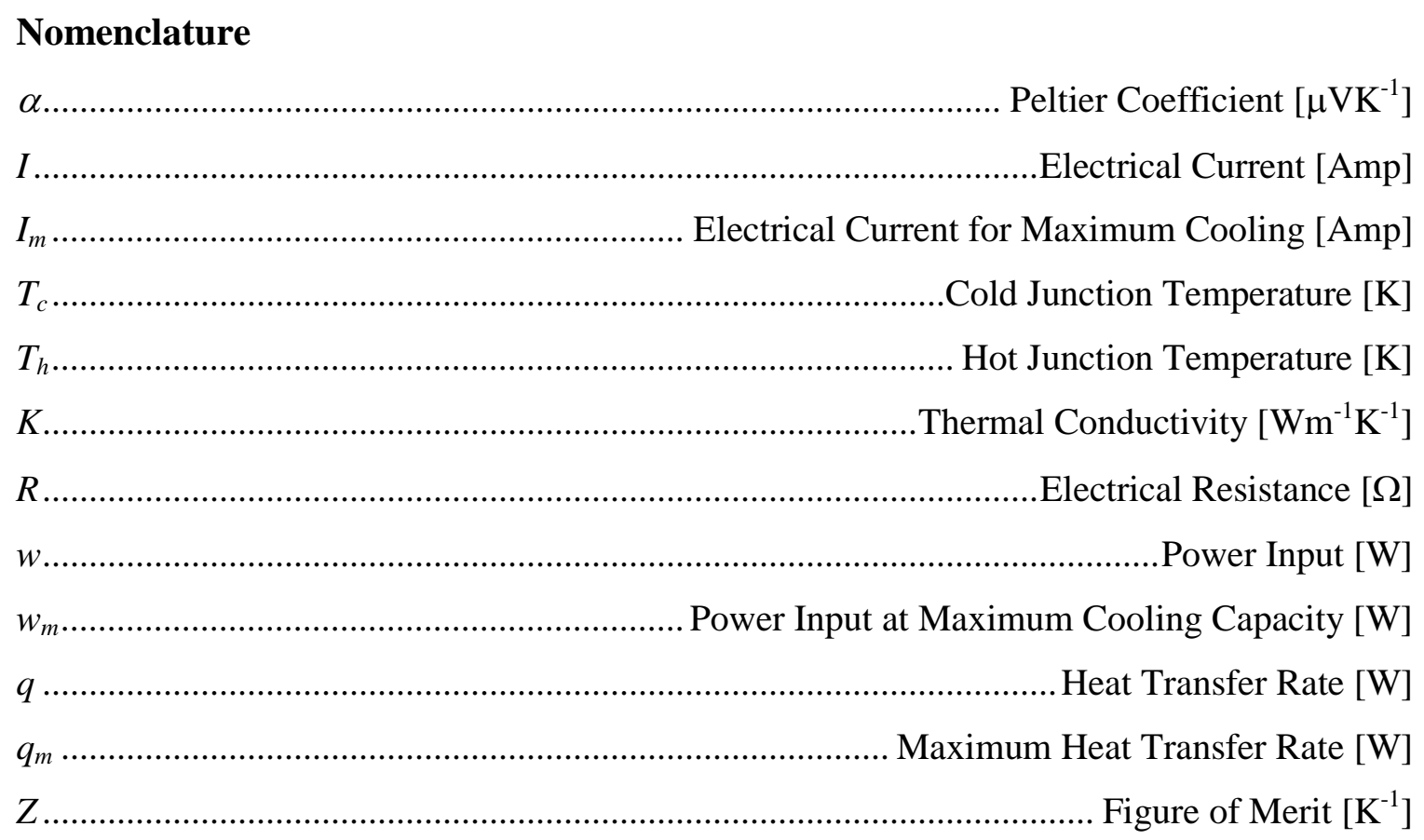

\section{Subcripts}

n ................................................. Properties associated with n-type semiconductor material

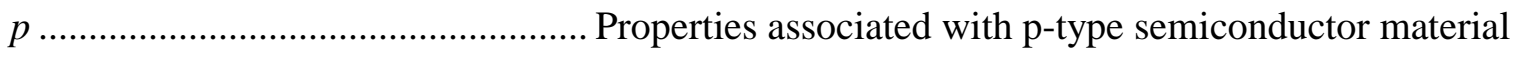




\section{1: Introduction}

The energy consumed by most domestic refrigerating products sold in the United States is regulated by the U.S. Department of Energy; and beginning in 2014, this regulation will be based on the test methods outlined in Appendix A of Subpart B of 10CFR430 (2010), which incorporates the test methods outlined in the Association of Home Appliance Manufacturers (AHAM) HRF-1-2008. This test is based on steady state operation of the unit with no door openings or user interaction in order to maintain a repeatable and reproducible test result. In order to compensate for the lack of interaction, the test is performed in a warm $\left(32.2^{\circ} \mathrm{C}\left(90^{\circ} \mathrm{F}\right)\right)$ environment. Most domestic refrigerating appliances employ a vapor compression based system to extract heat from the internal cabinet of the appliance. This is because vapor compression systems offer a range of benefits for this application including reasonable efficiency, scalability, and cost. The power consumption and cooling capacity of these products are well suited to properly function in an environment that is warmer than typical household conditions.

In recent years, however, some smaller niche products have come to market which employ thermoelectric cooling modules to maintain a cool cabinet. While thermoelectric cooling offers certain benefits such as no moving parts, no fluorinated refrigerants, and compactness, the limits of refrigerating capacity and efficiency for these modules are much smaller than that which can be obtained with a vapor compression system operating in the same range of temperature. In light of this, it is suspected that thermoelectric systems may not operate well enough in the warmer ambient conditions used for rating purposes. Therefore, the focus of this study was to examine whether such units can be tested according to the current rating method or if an alternative method is needed.

The physics governing the operation of thermoelectric modules is quite complicated. It is useful, however, to describe some key aspects of their operation; a more detailed discussion can be found in Goldsmid (2010). Thermoelectric cooling is based on the Peltier effect, which was discovered by J. Peltier in 1834 when he observed that if he passed an electrical current through the junction of two dissimilar materials, he could absorb or reject heat at the junction depending on the direction of the current. A sketch of a single junction thermoelectric cooling module is shown below in Figure 1.

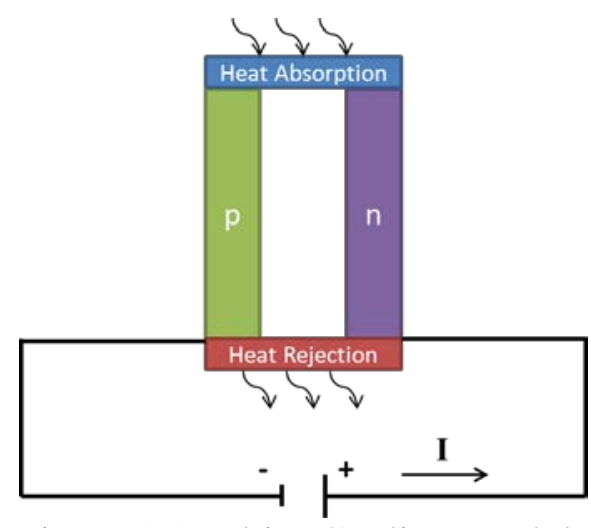

Figure 1.1 Peltier Cooling Module 
When a current is passed through a junction, the amount of Peltier cooling $(q)$ at the heat absorption junction is proportional to the difference in the Peltier coefficients of the materials $\left(\alpha_{p}, \alpha_{n}\right)$, the applied current $(I)$ and the temperature of the cold junction $\left(T_{c}\right)$. However, there are two other factors that need to be considered when examining the total obtainable cooling effect. The first factor is caused by the fact that heat will be transferred through the module via conduction from the hot junction to the cold junction because of the temperature difference generated by the process; this reduces the useful cooling effect by a term proportional to the thermal conductivity of the module $(\mathrm{K})$ and the temperature difference between the hot and cold junctions. The second factor is caused by the fact that heat will be generated in the module simply because the circuit is made up of real materials which have electrical resistance; this further reduces the useful cooling effect by another term proportional to the square of the applied current and the resistance $(\mathrm{R})$ in the circuit. The resulting expression for the obtainable cooling capacity of a thermoelectric module is shown in equation 1.

$q=\left(\alpha_{p}-\alpha_{n}\right) I T_{c}-K\left(T_{h}-T_{c}\right)-\frac{1}{2} I^{2} R$

The form of this equation is a concave down quadratic with respect to the applied current, I; therefore, there exists a maximum cooling capacity that can be obtained from a module. By setting the first derivative of this equation equal to zero, the maximum cooling capacity is obtained at the current $\mathrm{I}_{\mathrm{m}}$.

$I_{m}=\frac{\left(\alpha_{p}-\alpha_{n}\right) T_{c}}{R}$

The amount of power used to operate a thermoelectric device, shown in equation 3 , consists of the power used to drive the cooling effect plus the amount of energy that is ultimately turned into heat by passing an electrical current through a resistive material.

$w=\left(\alpha_{p}-\alpha_{n}\right) I\left(T_{h}-T_{c}\right)+I^{2} R$

Therefore, the Coefficient of Performance (COP) of the system, obtained by dividing equation 1 by equation 3 , is expressed in equation 4 .

$\frac{q}{w}=\frac{\left(\alpha_{p}-\alpha_{n}\right) I T_{c}-K\left(T_{h}-T_{c}\right)-\frac{1}{2} I^{2} R}{\left(\alpha_{p}-\alpha_{n}\right) I\left(T_{h}-T_{c}\right)+I^{2} R}$

The Coefficient of Performance (COP) at the current which provides the maximum cooling output is the parameter that is of most interest when considering thermoelectrics cooling devices. By substituting equation 2 into equation 4 and separating out all of the terms that consist of material properties, equation 5 is obtained.

$$
\frac{q_{m}}{w_{m}}=\frac{Z \frac{T_{c}^{2}}{2}-\left(T_{h}-T_{c}\right)}{Z T_{h} T_{c}}
$$


where:

$z=\frac{\left(\alpha_{p}-\alpha_{n}\right)^{2}}{R}$

The term Z, called the figure of merit, consists solely of material properties and has units of $\left[\mathrm{K}^{-1}\right]$. Since the figure of merit varies with temperature, it is often expressed as a nondimensional value being multiplied by the temperature, denoted ZT. Significant research has been performed recently to identify materials with a large figure of merit for materials that may potentially be used for thermoelectric cooling. Further research into materials have used various deposition and doping methods to enhance the figure of merit for candidate materials (Goldsmid, 2000). At the present day, alloys based on the $\mathrm{Bi}_{2} \mathrm{Te}_{3}$ system stand out as those with the largest figure of merit and are the state of the art for modern thermoelectric cooling systems. The dimensionless figure of merit (ZT) for these systems at $300 \mathrm{~K}$, within the expected range of operation for a domestic refrigerating appliance, is typically on the order of 0.95 (Encyclopedia of Materials, 2002; Terasaki, 2005; Tervo et al., 2009), although some researchers have indicated the possibility of pushing this value up to 1.1 (Yamashita et al, 2005). Using this value the maximum obtainable COP for a thermoelectric module operating between a $-17.8{ }^{\circ} \mathrm{C}\left(0^{\circ} \mathrm{F}\right)$ heat source and a $32.2^{\circ} \mathrm{C}\left(90^{\circ} \mathrm{F}\right)$ heat sink (the internal and external temperatures expected for a refrigerator-freezer under rating conditions) is 0.22 . For comparative purposes, the theoretical COP limit for a vapor compression system operating under these conditions is 5.1 and most commercially available domestic refrigerators achieve an efficiency of approximately $20 \%$ to $25 \%$ of this limit; i.e. with a COP in the range of 1.0 to 1.5 .

The recent influx of thermoelectric products was driven by the introduction of dedicated wine storage cabinets which are a relatively new product class. Wine chillers are described as cooled cabinets whose sole purpose is the storage of wine. They are required to maintain an internal storage temperature of $12.8^{\circ} \mathrm{C}\left(55^{\circ} \mathrm{F}\right)$ during energy consumption tests (AHAM, 2008) which is significantly warmer than most other refrigerating products and therefore requires a much lower amount of cooling capacity. Since this internal compartment temperature is an achievable condition for a thermoelectric unit operating in a home, where the expected ambient temperature is approximately $22.2{ }^{\circ} \mathrm{C}\left(72{ }^{\circ} \mathrm{F}\right)$, several dozen models of thermoelectric wine storage cabinets are now commercially available. Thermoelectric compact refrigerators, whose purpose is to maintain a cabinet temperature of $3.9^{\circ} \mathrm{C}\left(39^{\circ} \mathrm{F}\right)$ are also beginning to emerge as a commercially available product. In this study, three such units were examined with the intent of evaluating the appropriateness of energy testing according to existing methods. 


\section{2: Experimental Procedure}

The test setup was constructed in accordance with the Department of Energy's test procedure outlined in 10CFR430, Subpart B, Appendix A, 2010; details of the environmental chamber and data acquisition system can be found in Yashar and Park (2011). All of the temperature data were gathered using a personal computer and a multiplexed data acquisition unit. Table 2.1 below lists the measured quantities and the uncertainty associated with the $95 \%$ confidence level. All of the uncertainties reported in this document were calculated based on the measurement uncertainties listed in Table 2.1 and the equations listed in the Appendix of Yashar and Park, 2011, and are expressed at the $95 \%$ level of confidence.

Table 2.1 Measurement Uncertainty

\begin{tabular}{|c|c|c|}
\hline Measured Quantity & Measurement Device & $\begin{array}{c}\text { Uncertainty at 95 \% } \\
\text { confidence }\end{array}$ \\
\hline Temperature & Thermocouples & $\pm 0.1^{\circ} \mathrm{C}\left(0.2^{\circ} \mathrm{F}\right)$ \\
\hline Power & Digital Power Meter & Max $( \pm 0.5 \%, \pm 0.06 \mathrm{~W})$ \\
\hline
\end{tabular}

A series of tests were conducted to characterize the energy consumed by each thermoelectric appliance operating in two different ambient conditions. First, the energy consumption of each unit was measured in accordance with the existing test procedures for wine chillers and all refrigerators.

The AHAM test method requires that an elevated ambient temperature condition of $32.2^{\circ} \mathrm{C}\left(90^{\circ} \mathrm{F}\right)$ be maintained during the measurements. The elevated ambient test condition is used to compensate for the effects of the lack interaction (door openings, insertion of warm foodstuffs, etc.) that the unit would see during field use. However, with thermoelectric cooling modules, the temperature difference prescribed in the test method may require cooling loads that are beyond the maximum capacity of the modules. Therefore, the possibility of measuring the annual energy consumption with the same setup and control settings for each test subject, but with a more typical household ambient temperature $22.2^{\circ} \mathrm{C}\left(72.0^{\circ} \mathrm{F}\right)$ was examined. The results for each test subject are described in the following chapters of this report. 


\section{3: Thermoelectric 12-Bottle Wine Chiller}

The first unit studied was a small 33 liter (1.2 cubic foot) thermoelectric wine chiller designed to store 12 bottles of wine, shown in Figure 3.1. The cooled compartment consists of three-bottle storage at the bottom of the cabinet and three moveable metal racks designed to store three bottles of wine each. The temperature in the cabinet is controlled by an externally accessible thermostat controlling the thermoelectric module and air is circulated in the compartment by a small fan located at the rear.

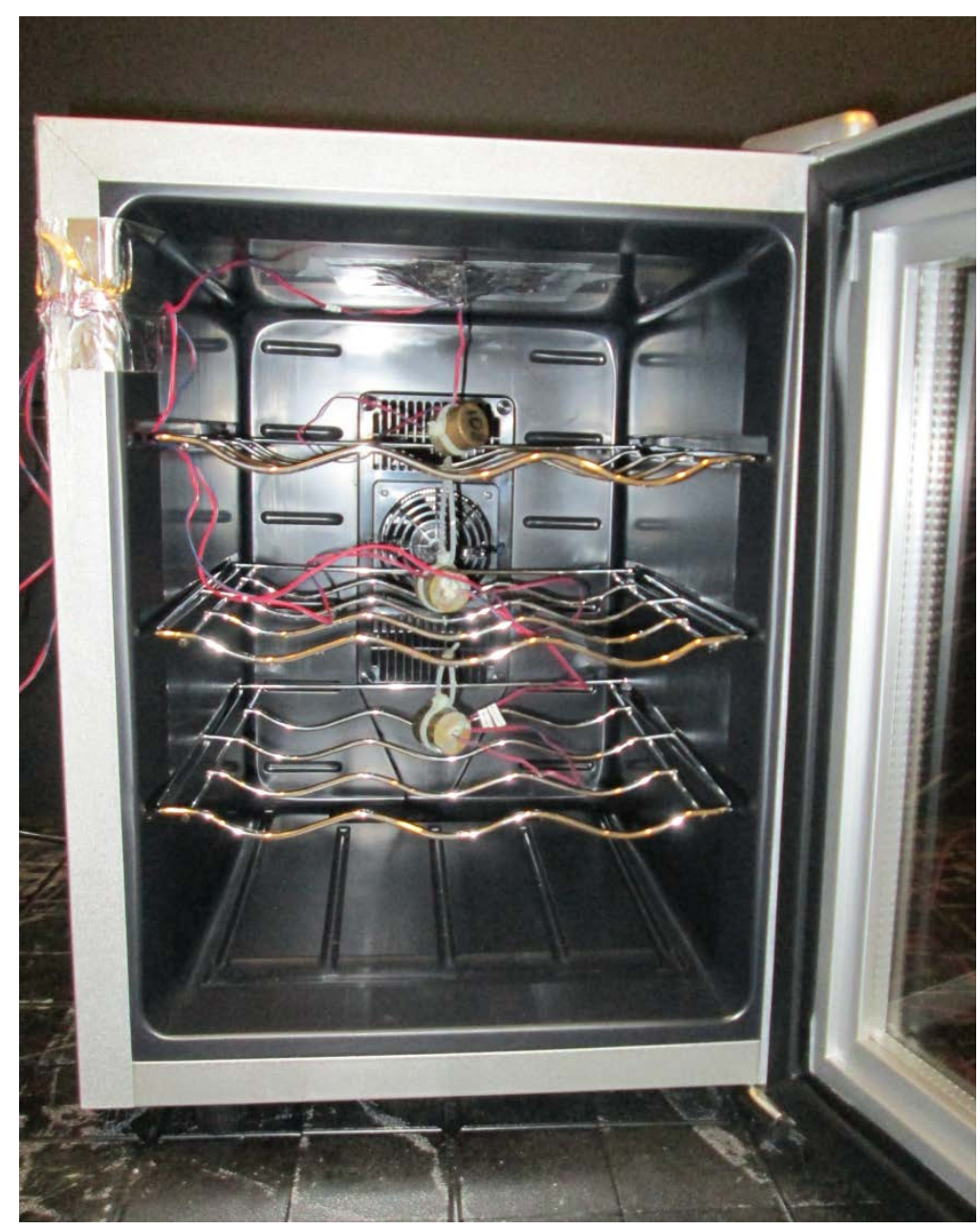

Figure 3.1 Thermoelectric 12-Bottle Wine Chiller

The internal compartment of the wine chiller was outfitted with three weighted thermocouples constructed in accordance with AHAM HRF-1-2008, which can be seen in the figure. The compartment temperatures reported are equal to the average of the three temperature measurements. We monitored the unit's power draw and the temperatures maintained in the compartment during steady state operation. The AHAM test procedure requires two measurements with different thermostat settings with the results bounding the prescribed target temperature of $12.8^{\circ} \mathrm{C}\left(55^{\circ} \mathrm{F}\right)$; this is generally accomplished by performing the first test at the median thermostat position and the 
second test at either the warmest or coldest thermostat position based on the results of the first test.

It should be noted that these units operate with variable power input to the cooling module and therefore run at a constant part-load condition for any given thermostat setting. Because of this, the system does not cycle on and off in the same way that most other systems operate. Each test period used in this analysis was defined to be 3 hours of steady state operation since the power draw and internal temperatures remained constant throughout. The results of the measurements in the $32.2{ }^{\circ} \mathrm{C}\left(90{ }^{\circ} \mathrm{F}\right)$ test room are shown in Table 3.1.

Table 3.1 Test Results for 12-Bottle Wine Chiller in $32.2{ }^{\circ} \mathrm{C}$ Test Room

\begin{tabular}{|l|c|c|c|}
\hline & Thermostat Setting & Compartment Temperature & Average Power Draw \\
\hline Test 1 & Mid & $17.0 \pm 0.1^{\circ} \mathrm{C}$ & $46.7 \pm 0.2 \mathrm{~W}$ \\
\hline Test 2 & Cold & $17.2 \pm 0.1^{\circ} \mathrm{C}$ & $46.6 \pm 0.2 \mathrm{~W}$ \\
\hline
\end{tabular}

These results showed no measurable difference in operation due to the change in thermostat setting. This is because the cooling system in this unit is not powerful enough to meet the set point temperature when operating in a $32.2{ }^{\circ} \mathrm{C}\left(90^{\circ} \mathrm{F}\right)$ environment. The cooling module was operating at its maximum output during both tests resulting in similar measurements of the compartment temperature and power draw. It is not appropriate to use the data acquired using the AHAM test method since that test method requires the unit maintain a $12.8{ }^{\circ} \mathrm{C}\left(55^{\circ} \mathrm{F}\right)$ internal condition in a $32.2{ }^{\circ} \mathrm{C}\left(90{ }^{\circ} \mathrm{F}\right)$ ambient condition.

For the second set of tests, the ambient temperature in the test chamber was maintained at $22.2^{\circ} \mathrm{C}\left(72{ }^{\circ} \mathrm{F}\right)$, a more conventional temperature that would be realized during field use. The results of these tests are shown in Table 3.2.

Table 3.2 Test Results for 12-Bottle Wine Chiller in $22.2^{\circ} \mathrm{C}$ Test Room

\begin{tabular}{|l|c|c|c|}
\hline & Thermostat Setting & Compartment Temperature & Average Power Draw \\
\hline Test 1 & Mid & $13.8 \pm 0.1^{\circ} \mathrm{C}$ & $14.4 \pm 0.1 \mathrm{~W}$ \\
\hline Test 2 & Cold & $10.4 \pm 0.1^{\circ} \mathrm{C}$ & $29.6 \pm 0.1 \mathrm{~W}$ \\
\hline
\end{tabular}

During this set of tests, the unit was capable of lowering the cooled compartment's temperature down to the set point during each measurement. Therefore this unit was able to vary the compartment temperature in response to the thermostat setting and the results of these two tests bounded the target temperature of $12.8^{\circ} \mathrm{C}\left(55^{\circ} \mathrm{F}\right)$. The prescribed test method requires that these results are linearly interpolated to determine the power draw at the target temperature, which yielded $19.0 \pm 0.1 \mathrm{~W}$, or in alternate units $167 \pm 1 \mathrm{kWh} / \mathrm{yr}$. 


\section{4: Thermoelectric 28-Bottle Wine Chiller}

The second unit studied is a 65 liter (2.3 cubic foot) thermoelectric wine chiller designed to store 28 bottles of wine, shown in Figure 4.1. The cooled compartment consists of four-bottle storage at the bottom of the cabinet and six metal racks designed to store four bottles of wine each. The temperature in the cabinet is controlled by variable power input to the thermoelectric module and air is circulated in the compartment by a small fan located at the rear.

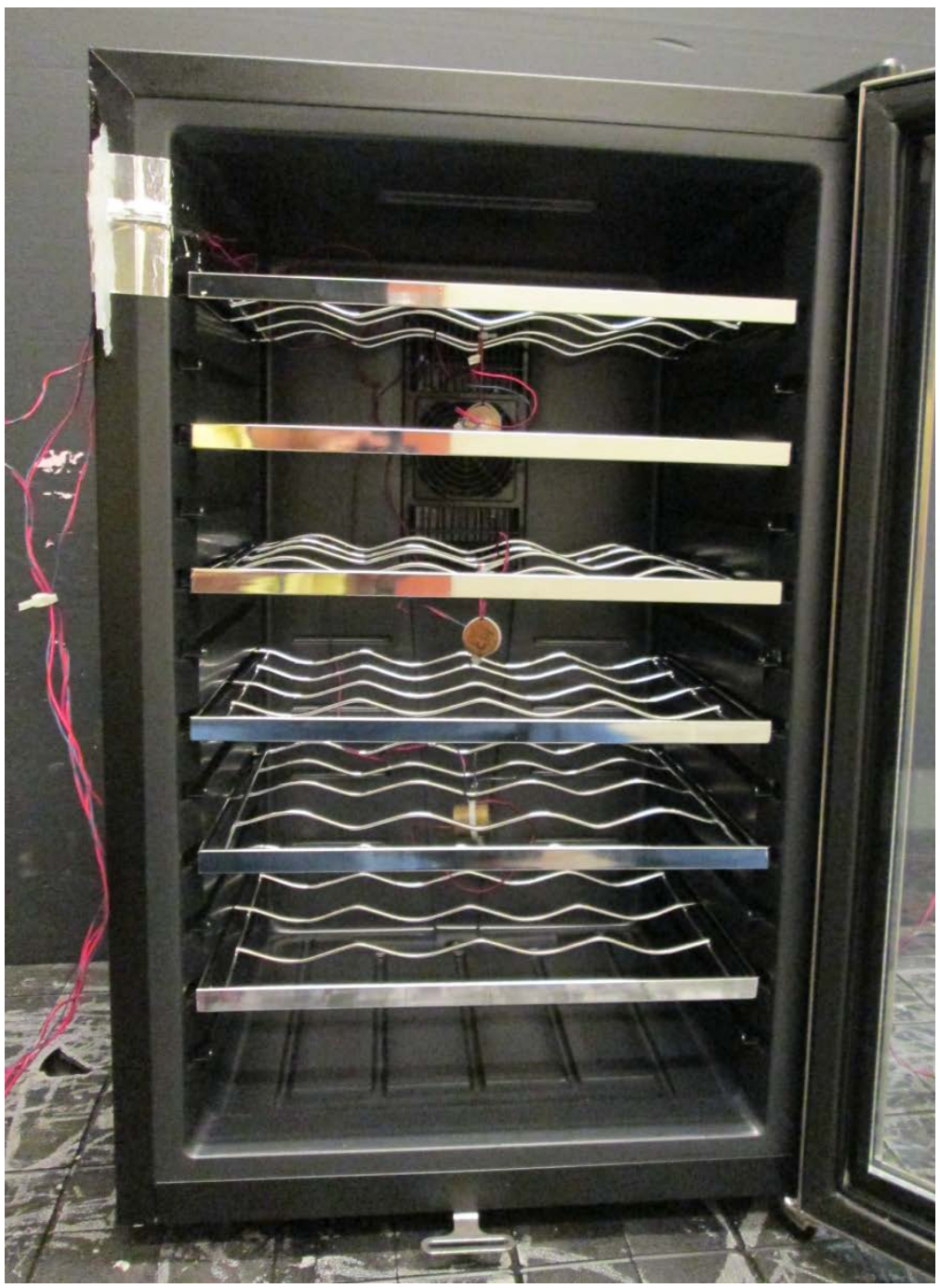

Figure 4.1 Thermoelectric 28-Bottle Wine Chiller 
The internal compartment of the wine chiller was outfitted with three thermocouples, which can be seen in the figure and a similar set of experiments to those performed on the 12-bottle unit was performed. Similar to the other tests, the test periods were all truncated to 3 hours due to the steady nature of operation. The results of the measurements in the $32.2{ }^{\circ} \mathrm{C}\left(90^{\circ} \mathrm{F}\right)$ test room are shown in Table 4.1.

Table 4.1 Test Results for 28-Bottle Wine Chiller in $32.2^{\circ} \mathrm{C}$ Test Room

\begin{tabular}{|l|c|c|c|}
\hline & Thermostat Setting & Compartment Temperature & Average Power Draw \\
\hline Test 1 & Mid & $18.0 \pm 0.1^{\circ} \mathrm{C}$ & $66.8 \pm 0.3 \mathrm{~W}$ \\
\hline Test 2 & Cold & $18.1 \pm 0.1^{\circ} \mathrm{C}$ & $66.8 \pm 0.3 \mathrm{~W}$ \\
\hline
\end{tabular}

These results also showed no measurable difference in operation due to the change in thermostat setting. Again, the cooling system in this unit is not powerful enough to lower the cabinet temperature to satisfy the thermostat set point when operating in a $32.2^{\circ} \mathrm{C}$ $\left(90^{\circ} \mathrm{F}\right)$ environment. The cooling module was operating at its maximum output during both tests resulting in similar measurements of the compartment temperature and power draw. For the second set of tests, the ambient temperature in the test chamber was maintained at $22.2^{\circ} \mathrm{C}\left(72{ }^{\circ} \mathrm{F}\right)$. The results of these tests are shown in Table 4.2.

Table 4.2 Test Results for 28-Bottle Wine Chiller in $22.2^{\circ} \mathrm{C}$ Test Room

\begin{tabular}{|l|c|c|c|}
\hline & Thermostat Setting & Compartment Temperature & Average Power Draw \\
\hline Test 1 & Mid & $15.6 \pm 0.1^{\circ} \mathrm{C}$ & $14.7 \pm 0.1 \mathrm{~W}$ \\
\hline Test 2 & Cold & $12.9 \pm 0.1^{\circ} \mathrm{C}$ & $24.0 \pm 0.1 \mathrm{~W}$ \\
\hline
\end{tabular}

During this set of tests, the unit was capable of varying the compartment temperature in response to the thermostat setting. It is interesting, however, that the unit did not meet the target temperature of $12.8^{\circ} \mathrm{C}\left(55^{\circ} \mathrm{F}\right)$ at the coldest setting, although it came very close. Although it is possible that this unit could attain the $12.8^{\circ}\left(55^{\circ} \mathrm{F}\right)$ condition in the $22.2^{\circ}\left(72^{\circ} \mathrm{F}\right)$ environment, it is more likely that the unit's controller did not allow it to bring the cabinet below this temperature since the results of the first round of tests suggest that it has more capacity since it can operate with a much larger power draw. In any regard, interpolating (or extrapolating in this case) the results of these tests to determine the power draw at $12.8{ }^{\circ} \mathrm{C}$ yields $24.6 \pm 0.1 \mathrm{~W}$, or in alternate units $216 \pm 1 \mathrm{kWh} / \mathrm{yr}$. 


\section{5: Thermoelectric Compact Refrigerator}

The final unit examined is a 71 liter (2.5 cubic foot) compact refrigerator, shown in Figure 5.1. The unit has a single compartment which included two moveable wire racks. It was outfitted with three thermocouples for testing.

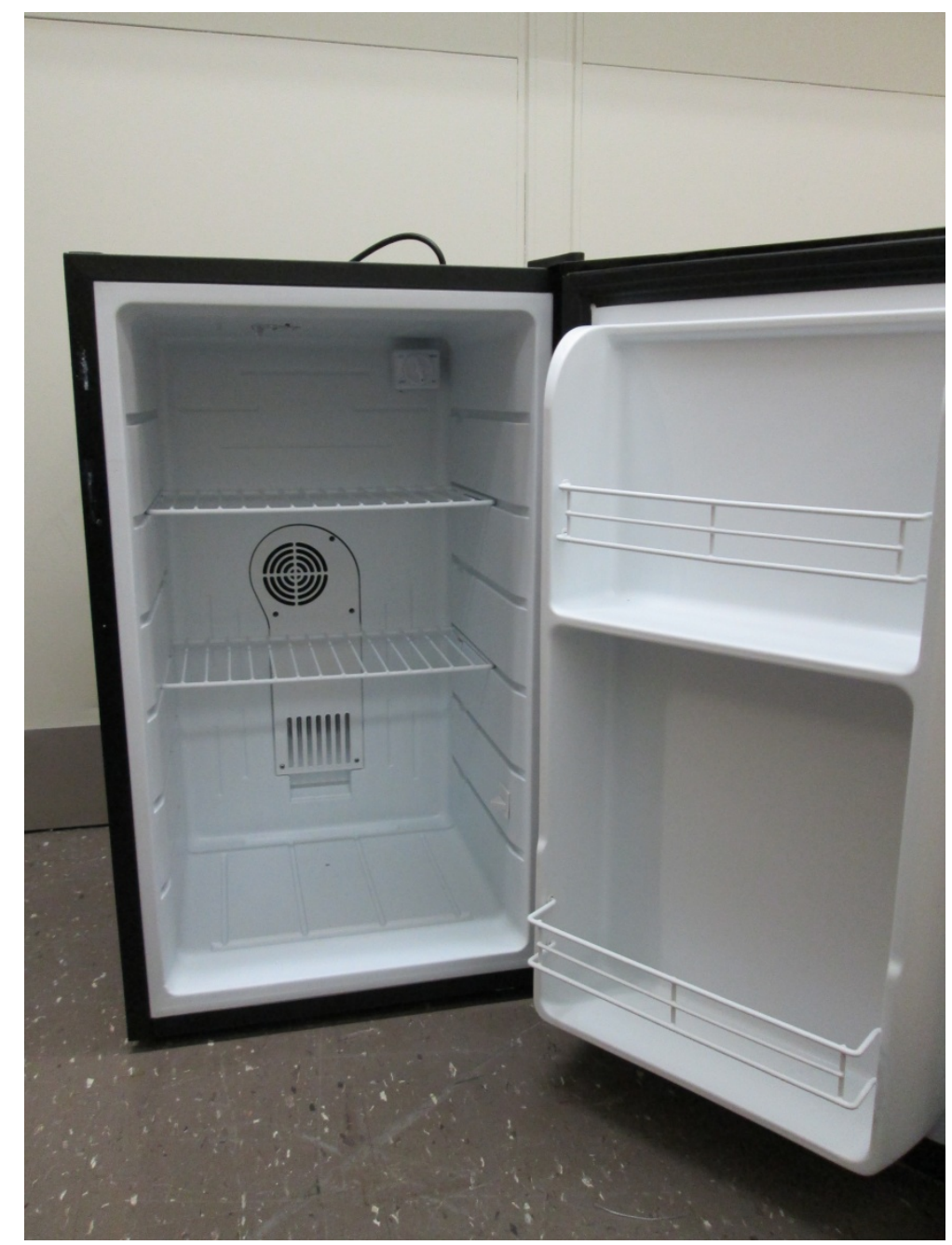

Figure 5.1 Thermoelectric Compact Refrigerator

A set of tests was performed according to the DOE test procedure for compact refrigerators. The unit was operated in a $32.2^{\circ} \mathrm{C}\left(90^{\circ} \mathrm{F}\right)$ environment and its power draw and internal temperature were recorded. Before examining the data, it is interesting to note that this unit's user manual stated that it included an automatic defrosting system. Upon examination of the test data, it was obvious that this defrost system merely implemented a shutdown of the cooling module for one hour every day and a half. Test data from this unit is shown Figure 5.2, the left vertical axis corresponds to the internal temperature (blue dashed line) and the right vertical axis corresponds to the power draw (red solid line). Nevertheless, a three hour steady state portion of the data was used for the analysis and the data recorded during the 'defrost' periods were excluded. The results of the measurements in the $32.2{ }^{\circ} \mathrm{C}\left(90{ }^{\circ} \mathrm{F}\right)$ test room are shown in Table 5.1. 


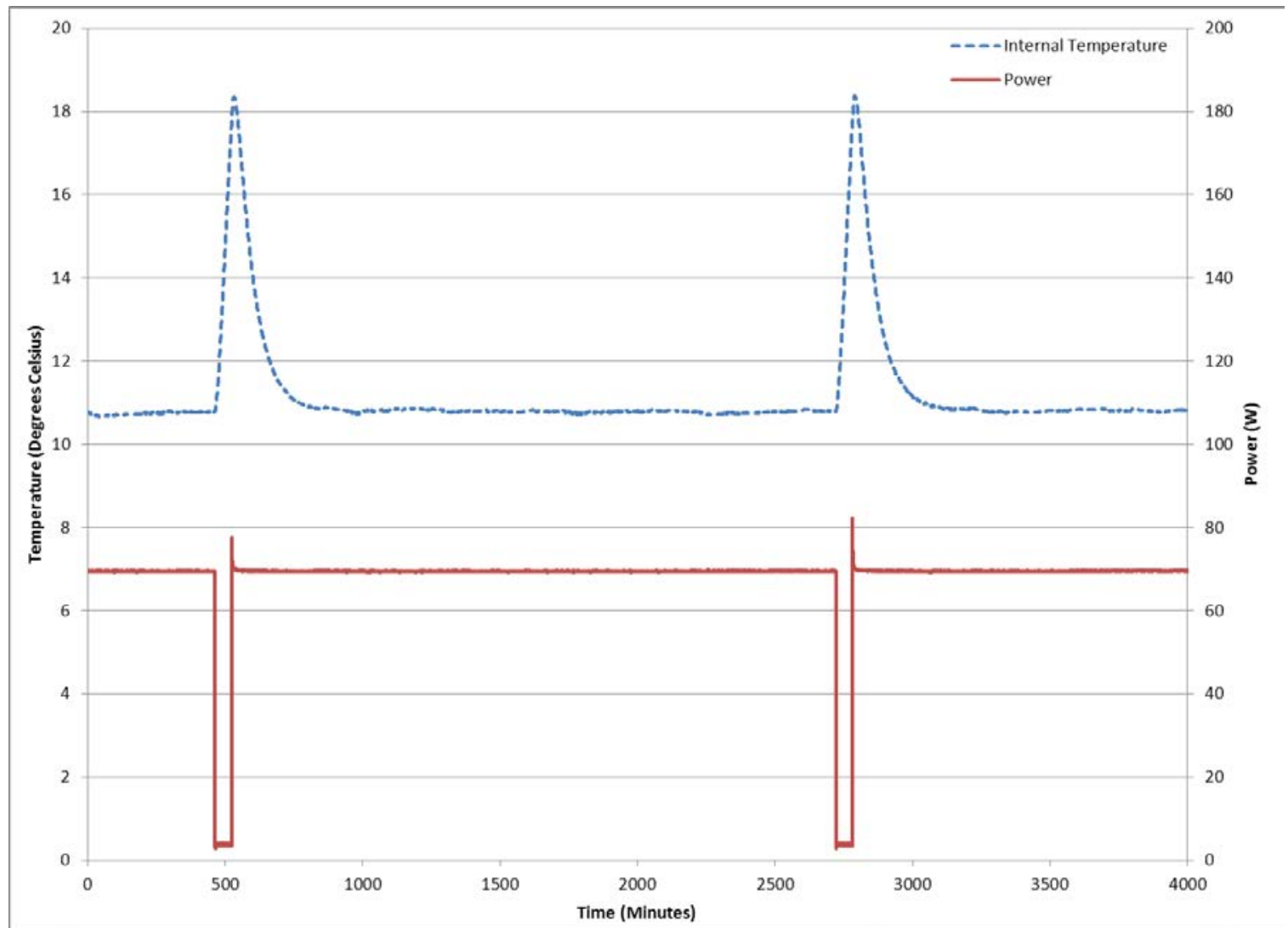

Figure 5.2 Compartment Temperature and Power Draw for Thermoelectric Compact Refrigerator

Table 5.1 Test Results for Thermoelectric Compact Refrigerator in $32.2{ }^{\circ} \mathrm{C}$ Test Room

\begin{tabular}{|l|c|c|c|}
\hline & Thermostat Setting & Compartment Temperature & Average Power Draw \\
\hline Test 1 & Mid & $10.8 \pm 0.1^{\circ} \mathrm{C}$ & $69.5 \pm 0.3 \mathrm{~W}$ \\
\hline Test 2 & Cold & $10.8 \pm 0.1^{\circ} \mathrm{C}$ & $69.5 \pm 0.3 \mathrm{~W}$ \\
\hline
\end{tabular}

Once again, these results showed no measurable difference in operation due to the change in thermostat setting because the cooling system in this unit is not powerful enough to meet the selected set point when operating in a $32.2^{\circ} \mathrm{C}\left(90^{\circ} \mathrm{F}\right)$ environment. The cooling module was operating at its maximum output during both tests resulting in similar measurements of the compartment temperature and power draw. For the second set of tests, the ambient temperature in the test chamber was maintained at $22.2^{\circ} \mathrm{C}\left(72{ }^{\circ} \mathrm{F}\right)$. The results of these tests are shown in Table 5.2.

Table 5.2 Test Results for Thermoelectric Compact Refrigerator in $22.2{ }^{\circ} \mathrm{C}$ Test Room

\begin{tabular}{|l|c|c|c|}
\hline & Thermostat Setting & Compartment Temperature & Average Power Draw \\
\hline Test 1 & Mid & $5.3 \pm 0.1^{\circ} \mathrm{C}$ & $32.5 \pm 0.2 \mathrm{~W}$ \\
\hline Test 2 & Cold & $2.7 \pm 0.1^{\circ} \mathrm{C}$ & $56.1 \pm 0.3 \mathrm{~W}$ \\
\hline
\end{tabular}


During this set of tests, the unit was capable of varying the compartment temperature in response to the thermostat setting. The defrost behavior for these tests was identical to that which was recorded during the tests in the $32.2^{\circ} \mathrm{C}\left(90^{\circ} \mathrm{C}\right)$ environment.

Interpolating the results of these tests to determine the power draw at $3.9^{\circ} \mathrm{C}\left(39^{\circ} \mathrm{F}\right)$ yields $45.2 \pm 0.6 \mathrm{~W}$, or in alternate units $396 \pm 5 \mathrm{kWh} / \mathrm{yr}$. 


\section{6: Summary and Conclusions}

In this study, the performance of three small thermoelectric refrigerating appliances was examined to determine whether or not the existing test methods could be used to rate these products. In each case, it was obvious that the current test method cannot be used for these products because the prescribed temperature difference between the internal compartment of the cabinets and the environment is too large for the thermoelectric units to overcome and they simply are not capable of achieving the test conditions.

For this reason the possibility of an alternate test condition was examined which decreased the difference between the required internal cabinet temperature and the temperature of environment where the cabinet is installed. When testing each of these products in a cooler environment, they were able to achieve the required storage temperatures; therefore this could be used as the basis for an alternative rating method for thermoelectric products.

Two thermoelectric wine chillers were examined as part of this study. Presently, the US Department of Energy does not regulate the energy consumption associated with wine chillers and therefore there is no federally mandated maximum energy standard for these products. However, a test method does exist in AHAM HRF-1-2008 and is regulations are in place in California and Canada. The rating method outlined in AHAM HRF-12008 requires that the energy consumption of a wine chiller be rated while operating in a $32.2^{\circ} \mathrm{C}\left(90^{\circ} \mathrm{F}\right)$ environment and maintaining a $12.8^{\circ} \mathrm{C}\left(55^{\circ} \mathrm{F}\right)$ internal temperature. Since the thermoelectric wine chillers were unable to achieve this condition, an ambient temperature of $22.2^{\circ} \mathrm{C}\left(72{ }^{\circ} \mathrm{F}\right)$ was selected as an acceptable alternative condition.

While exploring this alternative method, however, it is important to keep sight of the fact that the elevated ambient test condition was established for all other refrigerating products, and reducing the ambient temperature to rate these products will result in test measurements that are not comparable to measurements on other products that were rated using the existing test method. Therefore, if an approach using a lower ambient temperature is employed, the results should be scaled by an appropriate penalty factor in order to estimate the energy consumption that would be measured if the unit were capable of achieving the conditions prescribed in the test. Only then can the results of a test using the alternative method be compared to those of a unit tested with the conditions in AHAM HRF-1-2008.

Vapor compression based wine chillers operate across a $19.4 \mathrm{~K}\left(35^{\circ} \mathrm{F}\right)$ temperature difference $\left[32.2^{\circ} \mathrm{C}\left(90^{\circ} \mathrm{F}\right)\right.$ ambient and $12.8^{\circ} \mathrm{C}\left(55^{\circ} \mathrm{F}\right)$ internal] during their energy consumption test. The alternative test condition described in this report for thermoelectric units would require operation across a $9.4 \mathrm{~K}\left(17^{\circ} \mathrm{F}\right)$ temperature difference $\left[22.2^{\circ} \mathrm{C}\left(72{ }^{\circ} \mathrm{F}\right)\right.$ ambient and $12.8^{\circ} \mathrm{C}\left(55^{\circ} \mathrm{F}\right)$ internal], which requires a significantly smaller cooling load and therefore results in a significantly lower value for the energy consumption. Since the heat transfer into the cabinet from the ambient and the efficiency of the thermoelectric cooling module are both proportional to this temperature difference, the ratio of these two numbers (equation 7) is an obvious starting point for determining an appropriate penalty factor. Multiplying this penalty factor by the 
thermoelectric unit's power draw would result in a reasonable estimate of the amount of energy that the unit would consume if it were capable of meeting the required internal compartment temperature in a $32.2{ }^{\circ} \mathrm{C}\left(90^{\circ} \mathrm{F}\right)$ ambient temperature.

$\frac{32.2^{\circ} \mathrm{C}-12.8^{\circ} \mathrm{C}}{22.2^{\circ} \mathrm{C}-12.8^{\circ} \mathrm{C}}=2.06$

The data collected for the 12-bottle wine chiller and the 28-bottle wine chiller show that the energy consumption for these units operating in a $22.2^{\circ} \mathrm{C}\left(72{ }^{\circ} \mathrm{F}\right)$ environment is $167 \pm 1 \mathrm{kWh} / \mathrm{yr}$ and $216 \pm 1 \mathrm{kWh} / \mathrm{yr}$, respectively. Therefore, applying this penalty factor would result in rated values of $344 \pm 2 \mathrm{kWh} / \mathrm{yr}$ and $445 \pm 2 \mathrm{kWh} / \mathrm{yr}$, respectively, for these units.

We also examined a thermoelectric compact refrigerator. Unlike wine chillers, compact refrigerators are currently regulated by the US Department of Energy and the maximum allowable energy consumption for the size unit examined here is currently $326 \mathrm{kWh} / \mathrm{yr}$. The thermoelectric compact refrigerator tested here had similar issues to those seen with the wine chillers, and again we verified that testing in a $22.2^{\circ} \mathrm{C}\left(72{ }^{\circ} \mathrm{F}\right)$ environment was a possible alternative. Even in this relaxed test condition, the thermoelectric unit consumed more than $20 \%$ above the energy limit. However, in order to properly compare it to regulated vapor compression units of the same size we would have to multiply the measured energy consumption by an appropriate penalty factor. Using the same assumption as for the wine chillers, this factor should be:

$\frac{32.2^{\circ} \mathrm{C}-3.9^{\circ} \mathrm{C}}{22.2^{\circ} \mathrm{C}-3.9^{\circ} \mathrm{C}}=1.55$

which would result in a total rated value of $614 \pm 8 \mathrm{kWh} / \mathrm{yr}$, nearly twice the regulated limit for these products. 


\section{7: References}

AHAM, 2008. ANSI/ HRF-1-2008, Association of Home Appliance Manufacturers, Energy and Internal Volume of Refrigerating Appliances, Washington, DC.

Energy Conservation Program for Consumer Products: Test Procedures for Refrigerators, Refrigerator-Freezers, and Freezers; Final Rule and Interim Final Rule, Title 10 Code of Federal Regulations, Part 430, Subpart B, Appendix A (16DEC2010).

Goldsmid, H. J. Recent Trends in Thermoelectric Materials, Semiconductors and Semimetals Vol. 69, Ch.1 (Academic, 2000).

Goldsmid, H. J. Introduction to Thermoelectricity, Springer 2010 DOI 10.1007/978-3642-00716-3.

K. H. Jürgen Buschow, Robert W. Cahn, Merton C. Flemings, Bernard Ilschner (print), Edward J. Kramer, Subhash Mahajan, and Patrick Veyssière (updates), Encyclopedia of Materials: Science and Technology, 2001. ISBN: 978-0-08-043152-9 .

Terasaki, I. Introduction to Thermoelectricity (Ch 13). Materials for Energy Conversion Devices, J. Woodhead Publishing in Materials, Cambridge, 2005, pp. 339-357.

Tervo, J., Manninen, A., Ilola, R., and Hanninen, H., State-of-the-Art Thermoelectric Materials Processing, VTT 2009, ISBN 978-951-38-7184-0.

Yamashita, O. and Sugihara, S., High-performance bismuth-telluride compounds with highly stable thermoelectric figure of merit, Journal of Materials Science 40(2005) pp. 6439-6444.

Yashar, D. and Park, K.J., 2011. Energy Consumption of Automatic Ice Makers Installed in Domestic Refrigerators, NIST Technical Note 1697, NIST Gaithersburg, MD USA. 